\title{
Prospective application of metabolic ecology in plant ecology and agricultural science
}

\section{Opinion}

The metabolic ecology and allometric theory become flourishing and widely developed in the field of ecology and theoretical physics by recent decades..$^{1,2}$ The quantifiable laws from metabolic ecology, which are based on statistical regression out of observational facts and derived through basic physics, were considered as a major breakthrough of the contemporary theoretical ecology. Metabolic ecology with its self-consistency in theory and broad application perspective in practice has been though highly in the science community. ${ }^{2}$ Following the fundamental theory of metabolic ecology having been established, the relevant studies constantly continued, involving many branches of biology, ecology, and even expanding to economy. 2,3 Research paradigm of metabolic ecology needs improvement through multidisciplinary interaction, especially in plant ecology and agricultural science, which provide the platform for the relevant theoretical and practical development (Figure 1). On the spatial dimension, it would be a valuable attempt to clarify the relations between the community co-evolution and the plant diversity pattern formation in the framework of the spatial game theory and flow network analysis, which have the same basic principals in the models of metabolic ecology. ${ }^{3-5}$ Metabolic ecology theories, revealed the biological phenomena and the laws based on biological fractal structure and fluid mechanics. ${ }^{6}$ While the terrestrial ecosystem landscape also own the fractal structure like mountainous and basin areas, where have been of common recognition and quantitative measurement ${ }^{7-8}$ (Figure 2). A combination of metabolic ecology and macroscopic approaches like applying remote sensing technique and landscape ecology will bring more enhancements in the large-scale investigation of the vegetation observation and analysis. ${ }^{9-10}$ For the temporal dimension, there were many of investigations on the fractal structure of periodic fluctuation phenomena such as biological rhythm of the plants and the animal-plant interactions, such as the topics about climate change, migration of birds, hibernation and vertical migration of mammals based on the forage theories, ${ }^{11-13}$ are closely related to
Volume 4 Issue I - 2016

\author{
Wenzhao Wu, Zhouyuan Li, Yanni Zhang \\ School of Environmental,Tsinghua University, China
}

Correspondence: Zhouyuan Li, School of Environmental, Tsinghua University, China, Email zhouyuan.li2009@gmail.com

Received: June 27, 2016 | Published: July 01, 2016

substance metabolism and energy flows of the elements in ecosystems, however, that so far very limited work of systematic generalization, or quantitative research from the perspective of metabolic ecology has been carried out.

In the future, the promotion and deepening for the application of metabolic ecology to the plant and agricultural sciences require scientists and engineers, make efforts together in a strategically way. It was suggested to learn successful experience from former theories like landscape ecology, system dynamics method, and ecological network theory, ${ }^{13-16}$ to standardize and axiomatize the theoretical framework, to apply the research paradigm in practices, and to systematically construct the quantification indicators. In addition, user-oriented software making and integration, educational and commercial cases development, organizing societies to provide services for the industry and society should also be helpful to establish wider recognition and improve the value of the theories. It was expected that the methodology of metabolic ecology would enhance the new round of theoretical updates in plant ecology as providing deeper understanding on the mechanism of the structure-function of ecosystems by the different scales to effectively modernize the agricultural planning and management and improve the sustainability of the whole industry.

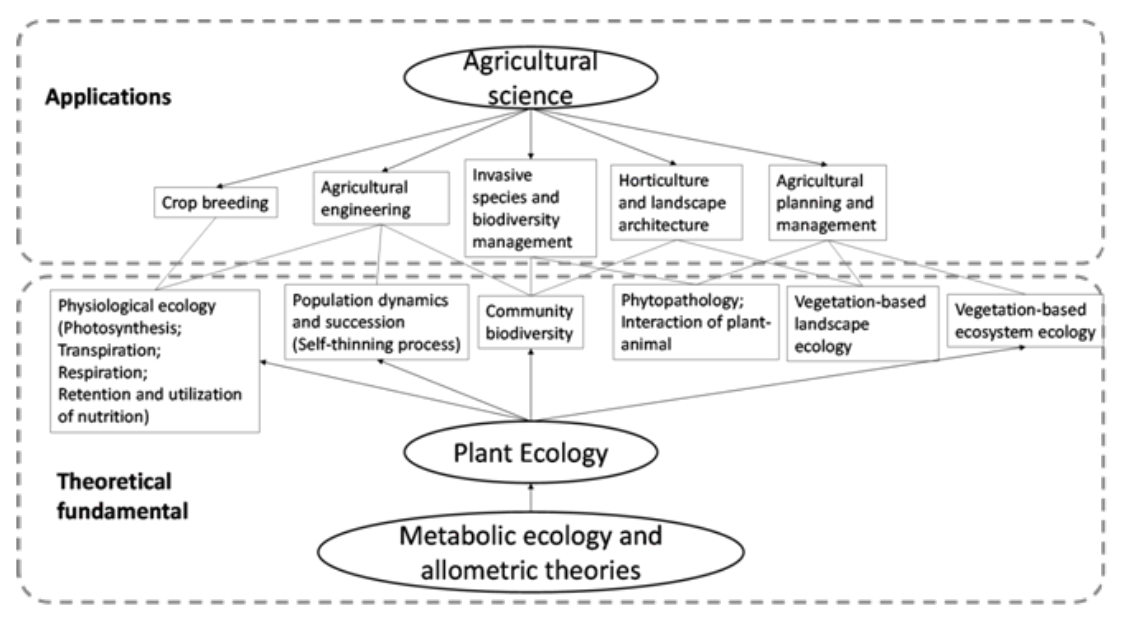

Figure I A general framework for the prospective application of metabolic ecology in plant ecology and agricultural science. 

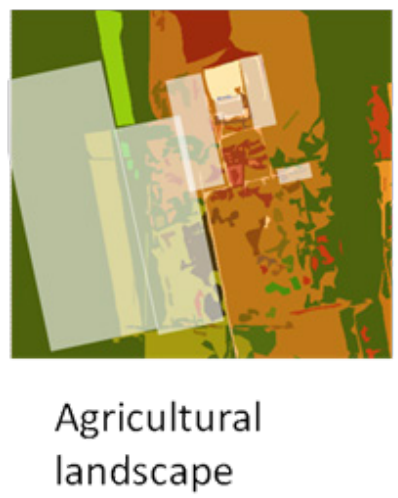
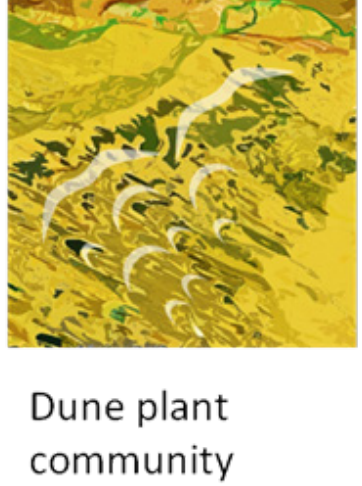

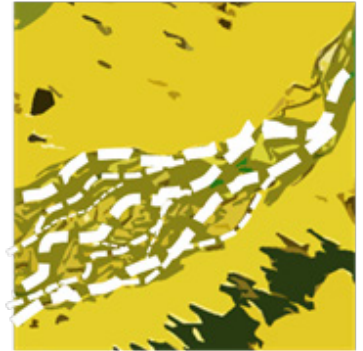

Basin grassland
community

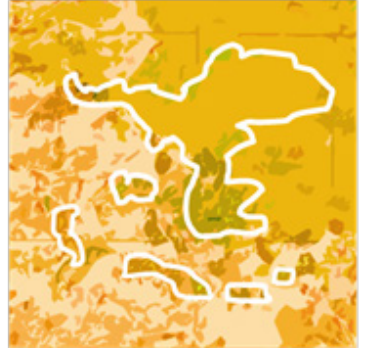

\section{Desert shrub community}

Figure 2 Different random fractal structures in natural vegetation landscape based on the remote sensing observation (interpretation from the imagery of Google Earth).

\section{Acknowledgements}

None.

\section{Conflict of interest}

The author declares no conflict of interest.

\section{References}

1. Brown JH, Gillooly JF, Allen AP, et al. Toward a metabolic theory of ecology. Ecology. 2004;85(7):1771-1789.

2. Marquet PA, Allen AP, Brown JH, et al. On theory in ecology. BioScience. 2014;64(8):701-710.

3. Zhang J, Li X, Wang X, et al. Scaling behaviors in the growth of networked systems and their geometric origins. Scientific reports. 2015;5.

4. Wang, Z, Brown JH, Tang Z, et al. Temperature dependence, spatial scale, and tree species diversity in eastern Asia and North America. Proceedings of the National Academy of Sciences. 2009;106(32):13388-13392.

5. Elser JJ, Fagan WF, Kerkhoff AJ, et al. Biological stoichiometry of plant production: metabolism, scaling and ecological response to global change. New Phytologist. 2010;186(3):593-608.

6. West GB, Brown JH, Enquist BJ. A general model for the origin of allometric scaling laws in biology. Science. 1997;276(5309):122-126.

7. Burrough PA. Fractal dimensions of landscapes and other environmental data. Letter to nature. 1981;294:240-242.

8. Feng Y, Liu Y. Fractal dimension as an indicator for quantifying the effects of changing spatial scales on landscape metrics. Ecological Indicators. 2015;53:18-27.
9. Li Z, Liu X, Niu T, et al. Ecological restoration and its effects on a regional climate: the source region of the yellow river, China. Environ Sci Technol. 2015;49(10):5897-5904.

10. Li Z, Liu X, Ma T, et al. Retrieval of the surface evapotranspiration patterns in the alpine grassland-wetland ecosystem applying SEBAL model in the source region of the Yellow River, China. Ecological modeling. 2013;270:64-75

11. Liu X, Toxopeus AG, Skidmore AK, et al. Giant panda habitat selection in foping nature reserve, China. Journal of wildlife management. 2005;69(4):1623-1632.

12. Si Y, Xin Q, de Boer WF, et al. Do Arctic breeding geese track or overtake a green wave during spring migration? Scientific reports. 2015;5.

13. Jiang Y, Bie CAJM, Wang T, et al. Hyper $\square$ temporal remote sensing helps in relating epiphyllous liverworts and evergreen forests. Journal of Vegetation Science. 2013;24(2):214-226.

14. Chen S, Chen B. Urban energy consumption: different insights from energy flow analysis, input-output analysis and ecological network analysis. Applied Energy. 2015;138:99-107.

15. Zhang J, Li X, Wang X, et al. Scaling behaviors in the growth of networked systems and their geometric origins. Scientific reports. 2015;5.

16. Fath BD, Jørgensen SE, Patten BC, et al. Ecosystem growth and development. Biosystems. 2004;77(1):213-228. 